\title{
El alcázar de Pastrana
}

\section{Enrique J. Fernández Tapia}

Universidad de Alcalá, Guadalajara, España, fernandez.tapia@uah.es

\begin{abstract}
In 1542 works began of the residence of Dona Ana de la Cerda, first lady of Pastrana, according traces of Alonso de Covarrubias. From the beginning the neighbors were opposed to such construction, because to carry out it, part of the wall of the villa was demolished. Furthermore by their appearance they argued that this really was the construction of a fortress, which was not allowed within four hundred steps of such walls. The building that was not completed, resembles lesser scale, to another works of the architect, like the Alcázar of Madrid and of Toledo. They emphasize its coffered Plateresque and sockets Mudejar tiles. It served as a prison between 1581 and 1592 the Princess of Eboli. Finaly It was acquired in 1997 by the University of Alcalá, in a pitiful condition, that had undertaken its restoration and rehabilitation.
\end{abstract}

Keywords: Pastrana, palacio ducal.

\section{Introducción}

Pastrana, declarada conjunto histórico artístico desde 1966, se sitúa en el corazón de la Alcarria, en una empinada ladera en la que brotan manantiales y entre dos arroyos que desembocan en el río Arlés y este a su vez en el Tajo.

La villa de Pastrana fue adquirida a la corona por doña Ana de la Cerda, condesa de Mélito y viuda de Don Diego Hurtado de Mendoza en 1541, tras haber pertenecido a la orden de Calatrava desde su nacimiento en el s. XIII, como una aldea de repoblación (Nieto, 1999). La condesa pretendía hacer de la villa la cabeza de su señorío, dentro de la extensa e innovadora política dinástica desarrollada por la familia Mendoza (Alegre, 2003). Sin perder el tiempo hizo uso de los poderes que entendía le habían sido transferidos con la compra para llevar a cabo este proyecto. Con estos fines, cortó más de setenta mil pies de árboles, construyó caleras y puso guardas en los montes, lo que el concejo consideró que era un uso abusivo de las tierras concejiles (Prieto, 1986). Estas acciones y el ímpetu con el que se asumió el señorío, propiciaron que desde el primer momento las relaciones con los habitantes de la villa fuera muy malas, acabando en manos de la justicia. Pero la situación continúo empeorando pues además la condesa tenía previsto construir una casa-fuerte o fortaleza y para ello encarga a Alonso de Covarrubias su diseño. En 1542 se entregan las trazas y se comienzan las demoliciones y trabajos en el solar que se situaba en el exterior del extremo nornordeste del recinto amurallado. Los vecinos veían como una amenaza su construcción y se opusieron de nuevo ante la justicia argumentando: que las leyes del reino prohibían este tipo de construcciones, que el emplazamiento pretendido se situaba a tan sólo ocho o diez pasos y no a cuatrocientos como se especificaba en la carta de compra, afectando además a un trozo de la cerca o muralla que había sido construida y mantenida por el concejo (Prieto, 1986). La Real Chancillería de Valladolid, dio parcialmente la razón a la que era la primera señora de la villa, pues si bien era cierto que 
estaba prohibida la construcción de fortalezas, en este caso el rey había concedido, por un precio mayor en la venta, una licencia especial, que acabó permitiendo la construcción de lo que según los vecinos no era una casa-fuerte sino una fortaleza, que cuando se finalizase sería una de las fuertes del reino (Prieto, 1986).

No se trataba tan sólo de la construcción una fortaleza sino de una operación urbanística de ampliación del recinto amurallado, que acogía al edificio y sus jardines circundantes, precedidos de una gran plaza que amplía la perspectiva de la fachada sureste del mismo, que queda presidiéndola (Nieto, 1999).

El exterior del edificio, se asemeja, aunque en menor escala, a otras obras de dicho arquitecto, como el Alcázar de Madrid o el de Toledo.

El edificio sirvió de cárcel entre 1581 y 1592 a la princesa de Éboli y en él se alojó Santa Teresa, durante unos meses para llevar a cabo la fundación de sus conventos en la villa. En el s. XVIII pasó a pertenecer a la compañía de Jesús que lo compartimentó en viviendas para arrendar, tras su expulsión pasó a la curia de Toledo y en 1956 a la de Sigüenza. En 1941 el palacio fue declarado conjunto histórico artístico, por lo que en 1947 el arquitecto F. González Valcárcel realiza un proyecto con el fin de evitar el hundimiento de las cubiertas. A esta le suceden hasta los años 80, otras intervenciones de diverso alcance, destinadas a evitar su ruina.

Finalmente en 1997, fue adquirido por la Universidad de Alcalá, que se hace cargo del edificio en un estado lamentable de conservación. Tras el realojo de los inquilinos que todavía permanecían en el edificio, se procedió a la redacción del proyecto y a acometer su restauración y rehabilitación como Centro Universitario de Investigación Medioambiental y Desarrollo Rural, con el apoyo de fondos europeos.

El edificio de trazas renacentistas, tiene forma cuadrangular y se desarrolla alrededor de un patio central, del que nunca llegó a realizarse la galería porticada, que teóricamente debía permitir la comunicación a las diferentes estancias, la que existía antes de esta última intervención pertenecía a un proyecto del arquitecto J.M. Merino de Cáceres. El edificio se proyectó con cuatro torres una en cada esquina, de las que sólo se terminaron las dos del alzado sur.

El programa del proyecto se distribuye de la siguiente manera: en las crujías este y oeste de planta semisótano se situaban dos grandes caballerizas que han sido reacondicionadas como salón de actos y cafetería respectivamente En planta baja, además del gran zaguán de entrada se han dispuesto despachos, aulas y una gran biblioteca. La planta noble del edificio donde se encuentra el salón del trono y la antigua capilla y otras salas, se han dispuesto aulas, seminarios y salas de exposiciones. Finalmente la planta segunda se ha destinado a habitaciones. La superficie total es de 7.438 metros cuadrados y 2.645 de jardines.

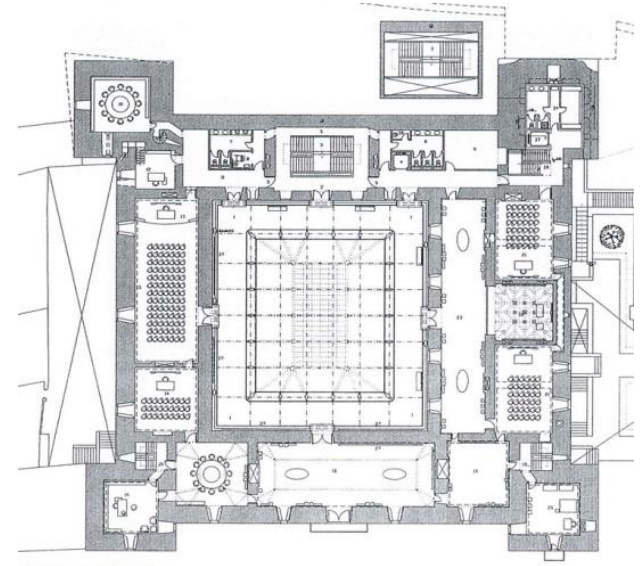

Fig. 1- Plano de planta baja del estado reformado (James Manson, 2005)

El inmueble se encuentra encajado en la ladera de la montaña con un desnivel más de $15 \mathrm{~m}$ entre el punto más alto y el más bajo, que es el de la fachada principal, que preside desde el flanco norte, la llamada plaza de La Hora. Los muros son de mampostería, pero es de resaltar la obra de cantería de reviste sus fachadas exteriores, así como las jambas y dinteles de sus huecos. 


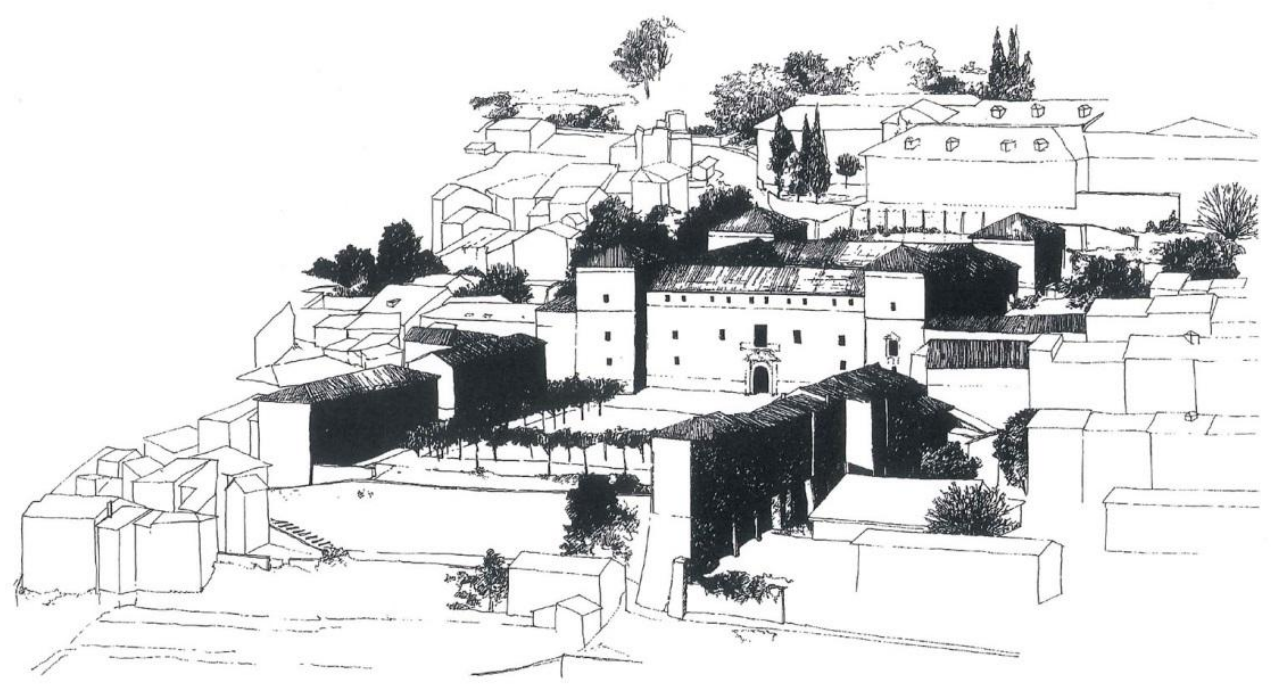

Fig. 2- Vista general del palacio en la plaza de la Hora tras la intervención.

En el interior destacan el zaguán en planta baja y el salón del trono, sus estancias anexas y la capilla en la planta noble, con sus artesonados de estilo plateresco y sus zócalos de azulejería de estilo mudéjar.
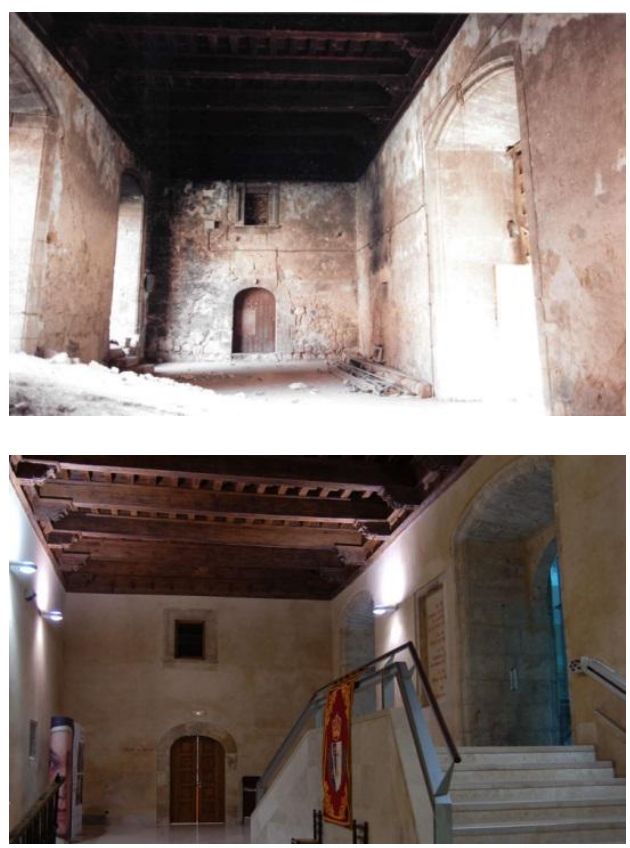

Fig. 3- Zaguán de entrada antes y después de la intervención. (James Manson, 2005).

\section{La intervención}

La desaparición de casi todo el patrimonio documental del palacio, ha hecho que la intervención tenga que basarse en los resultados de las excavaciones arqueológicas y en la constante observación del edificio.

Como criterios fundamentales se han conservado y restaurado mediante técnicas tradicionales y modernas, todos los elementos originales que se conservaban, como fábricas, bóvedas, viguerías de madera, azulejerías y artesonados. También se ha recuperado la estructura espacial original, incompleta y desfigurada por las intervenciones, más o menos afortunadas llevadas a cabo durante siglos.

Fruto del estudio y compresión del edificio, ha sido posible la toma de decisiones que han conducido a la finalización del trazado incompleto del mismo, atendiendo sobre todo a los resultados de las excavaciones arqueológicas, que entre otros resultados descubrieron las cimentaciones de las torres inacabadas noreste y noroeste. También se ha construido la necesaria, galería del patio, lo que permite un correcto funcionamiento de las circulaciones en planta baja y primera, mediante un lenguaje totalmente moderno. 

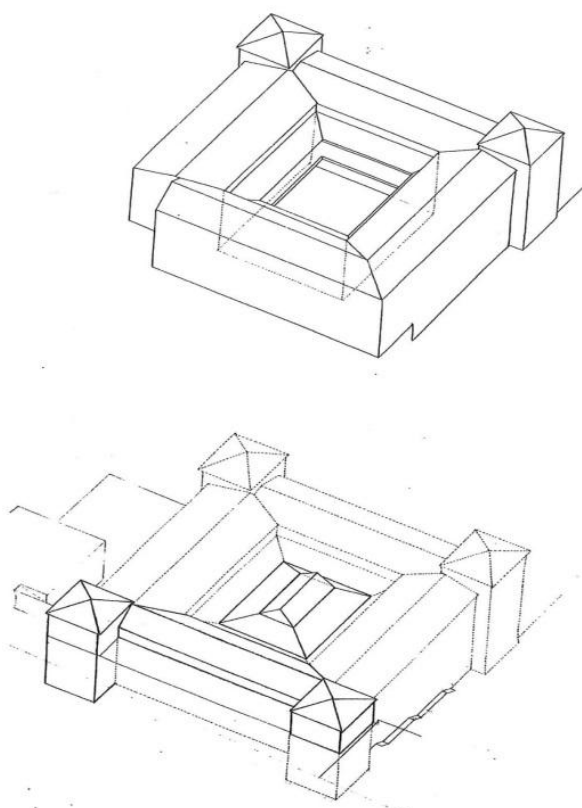

Fig. 4- Perspectiva esquemática del antes y después de la intervención.

Además se ha acometido la cubrición y el cerramiento del propio patio central, lo que ha mejorado enormemente las circulaciones en planta baja y la consecución de una mayor funcionalidad de dicho espacio.

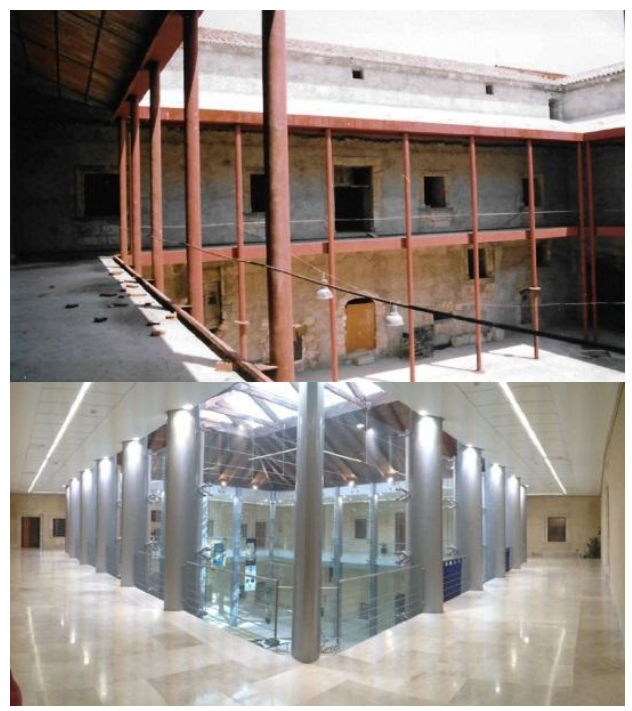

Fig. 5- Medussa blue (James Manson, 2005)
Por la importancia que suponen para un edificio de estas características, se ha dedicado especial cuidado a la resolución de las cubiertas. Dado que ninguna de las que existían previamente eran originales y tras estudiar detenidamente su estado de conservación se procedió a su sustitución atendiendo a unas directrices de alta durabilidad y resistencia. Bajo la teja árabe se ha colocado un tablero de chapa galvanizada con una capa de mortero con un mallazo, apoyado sobre correas metálicas y cerchas de tubo de acero, diseñadas para dejar pasar entre sus barras una pasarela de mantenimiento junto a la que discurren los añillos de distribución de las diversas instalaciones.

A pesar de que la situación general de las fábricas no era especialmente malo, ha sido necesario actuar sobre la práctica totalidad de los dinteles de los huecos interiores del edificio, recolocando las claves en su posición original. Los elementos más deteriorados eran los del pórtico de la puerta de entrada al edificio, algunos de los canecillos de los aleros y las jambas de muchos huecos de puertas y ventanas.

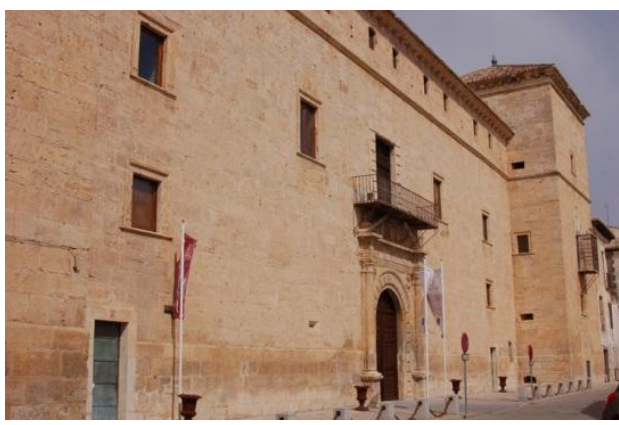

Fig. 6- Fachada principal.

Para la finalización de las dos torres incompletas, la reposición de las piezas faltantes o para la sustitución de las gravemente deterioradas, se localizó una vieja cantera en las proximidades, con piedra de similares características a las del palacio, pero los trámites para su explotación era tan complicados, que tras su estudio se desestimó su aprovechamiento, utilizándose en su lugar piedra caliza de Campaspero. Para las pequeñas faltas se emplearon morteros de resinas y árido de piedra similar. Para hacer más patente si cabe la 
diferenciación entre los sillares antiguos y modernos, a estos últimos se les dio un acabado en bujarda fina, frente al trinchante existente.

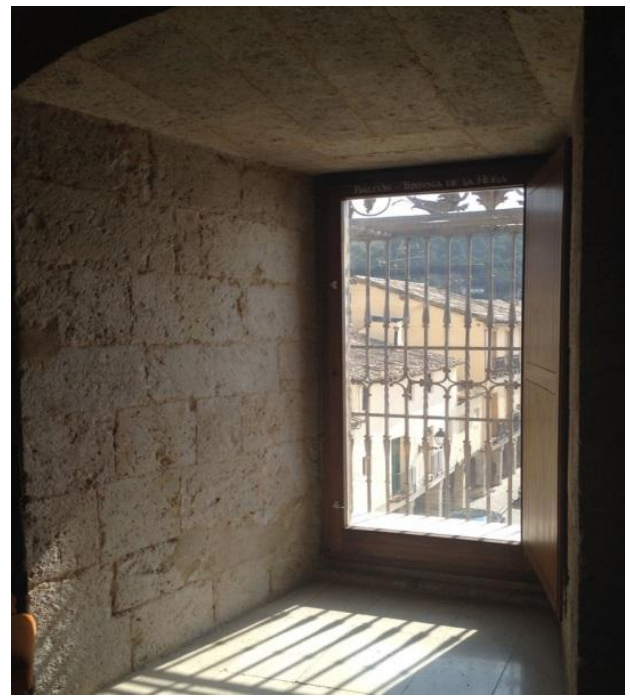

Fig. 7- Acceso al balcón-mirador donde se supone estuvo recluida la princesa de Éboli.

En el punto opuesto de conservación se encontraban las carpinterías y las estructuras de madera, presentado un elevado nivel de deterioro general. El mal estado de las cubiertas favorecía que se viesen afectadas por todo tipo de xilófagos (pudrición blanca y parda, carcoma grande $\mathrm{y}$ pequeña $\mathrm{y}$ termitas). Tras los tratamientos fungicidas $\mathrm{e}$ insecticidas $\mathrm{y}$ siguiendo los mismos criterios de máximo respeto hacia los elementos originales, se procedió al saneamiento de los elementos de madera.
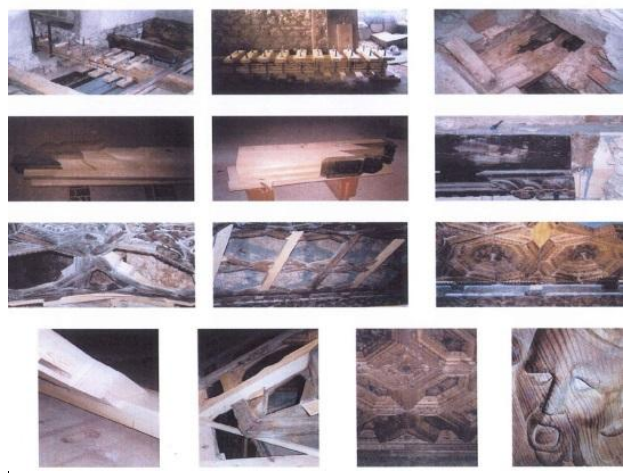

Fig. 8- Trabajos de restauración de la madera.
Se realizaron un gran número de prótesis de madera laminada en las cabezas de las vigas, así como el refuerzo de los forjados para que pudiesen aguantar las modernas solicitaciones de la normativa actual requiere.

En cuanto a los artesonados, atribuidos a los alarifes madrileños Justo de la Vega y Cristóbal de Nieva (Herrera, 1992), ha sido necesario en algunos casos su desmontaje y posterior montaje, para corregir las deformaciones que habían ido adquiriendo a lo largo de los años y que hacían peligrar la estabilidad del conjunto. Finalmente y tras una limpieza afondo, se aplicó a toda la estructura de madera, un tratamiento de protección y un barniz de poro abierto, tiñendo las zonas de madera nueva pero sin intentar su mimetismo.
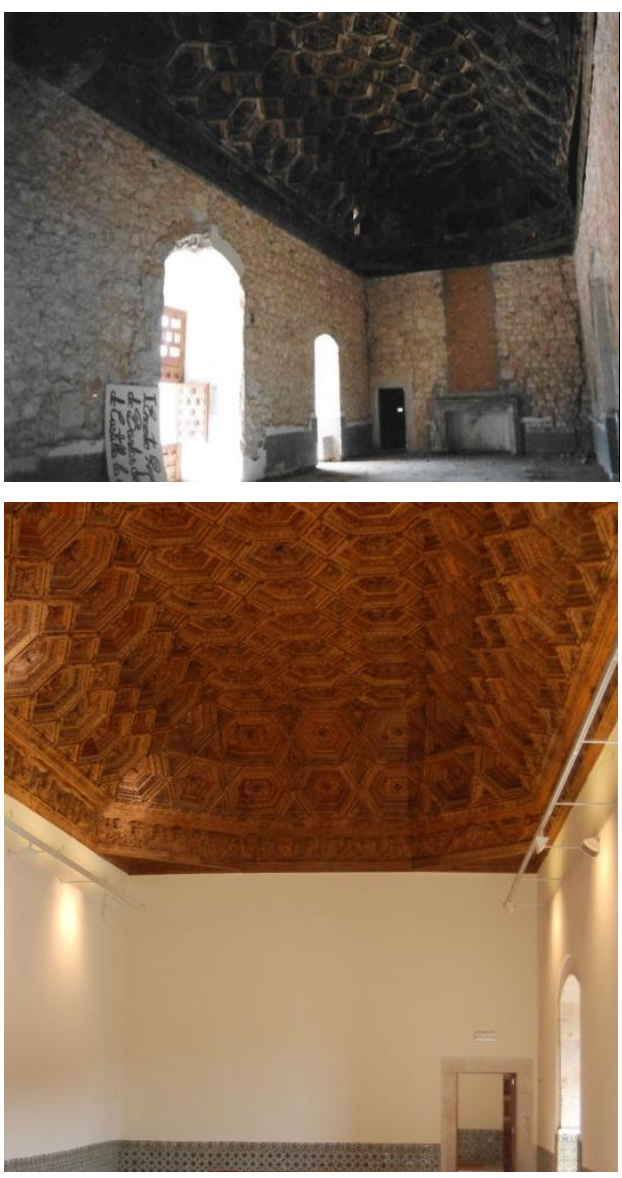

Fig. 9- Salón del trono, antes y después. 
Los azulejos existentes en el edificio fabricados en origen siguiendo la técnica de la cuenca o arista, proveniente del siglo XVI. En este caso, su estado podemos calificarlo comparativamente de bueno, considerándolo de forma general. Aunque se había detectado inicialmente la perdida de gran cantidad de las piezas en algunas salas, fue una de las gratas sorpresas que acontecieron durante las obras, el que apareciesen casi todas ellas, tapiadas tras un tabique, bajo un arco del muro de sótano de la torre noroeste.

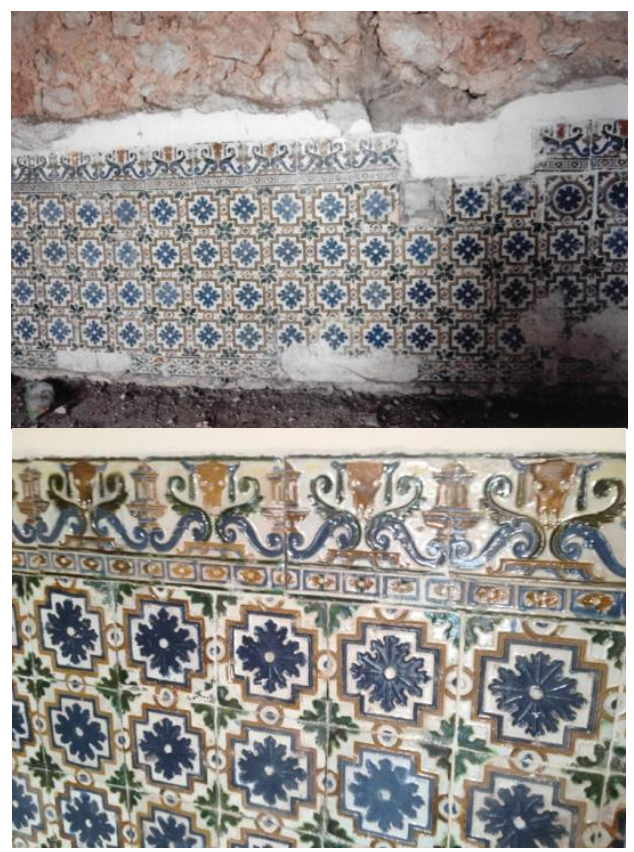

Fig. 10-Zócalo de azulejos, antes y después.

Las piezas fueron tratadas una por una, de acuerdo a su estado de conservación. En general se limpiaron, se fijó la capa vítrea donde se encontraba mal adherida y se estucó y se reintegró la capa pictórica y de protección donde se había perdido, evitando los añadidos no documentados.

La implementación de las instalaciones en un edificio que no estaba pensado para ello, ha supuesto una de las tareas más complicadas de llevar a cabo, pues se buscaba en todo momento hacerlo de la forma menos traumática posible para las fábricas y artesonados.
Las centralizaciones generales de producción se sitúan en los edificios de servicio existentes en el jardín de la parte superior, con un buen acceso desde el exterior.

La distribución de los trazados horizontales de las instalaciones eléctricas y de comunicación discurren bajo los encintados perimetrales de piedra caliza del solado. Para los trazados principales se utilizaron los espacios del bajo cubierta, conseguidos con las nuevas cerchas y los falsos techos de las nuevas galerías del patio. En cuanto a los trazados verticales se pudieron aprovechar los tiros de las antiguas chimeneas que existían en el edificio, los patinillos creados al efecto, en los muros al final de las crujías. En el caso de la galería del patio fue necesario implementar unos elementos verticales adosados a los muros para alojar las bajantes de la cubierta y otras instalaciones.

En términos generales la intervención en el palacio ducal de Pastrana ha seguido los criterios básicos que la Universidad de Alcalá ha venido utilizando durante años en la recuperación de su patrimonio histórico y que le ha traído diversos reconocimientos nacionales e internacionales.

\section{Notas}

Ficha técnica de la intervención:

Promotor: Universidad de Alcalá.

Proyecto y dirección facultativa: Antonio Fernández Alba, José Luis Castillo Puche y Carlos Clemente San Román, arquitectos, Baltasar Palomeque Abad y Enrique J Fernández Tapia, arquitectos técnicos, Antón García Villar y Amparo Andreu Comes, ingenieros.

Arqueología: José E. Benito, Dionisio Liebana y Ildefonso Ramírez, arqueólogos.

Empresa constructora: UTE, CYM YañezSulzer. Ignacio Gual, Mayte Lavín y Anastasio León, arquitectos técnicos.

Estructuras: Enrique Nuere Matauco, arquitecto, Luis Casas López- Amor, ingeniero.

Cantería: Pelayo Seoane y José Andrés Seoane, canteros.

Yesos y bóvedas: Carlos Martín, maestro yesero. 
Las fotografías del estado original y del proceso constructivo proceden del Archivo General de la Universidad de Alcalá, al igual que los dibujos, cuya autoría corresponde a la arquitecta Candelaria Alarcón.

Para obtener una imagen gráfica de lo que supuso la ampliación urbanística para la trama urbana, antes y después de la ampliación promovida por la condesa de Mélito, ver el plano al respecto recogido en la obra de Nieto y Carbajal (1999), sobre los jardines de la villa de Pastrana, pag. 59.

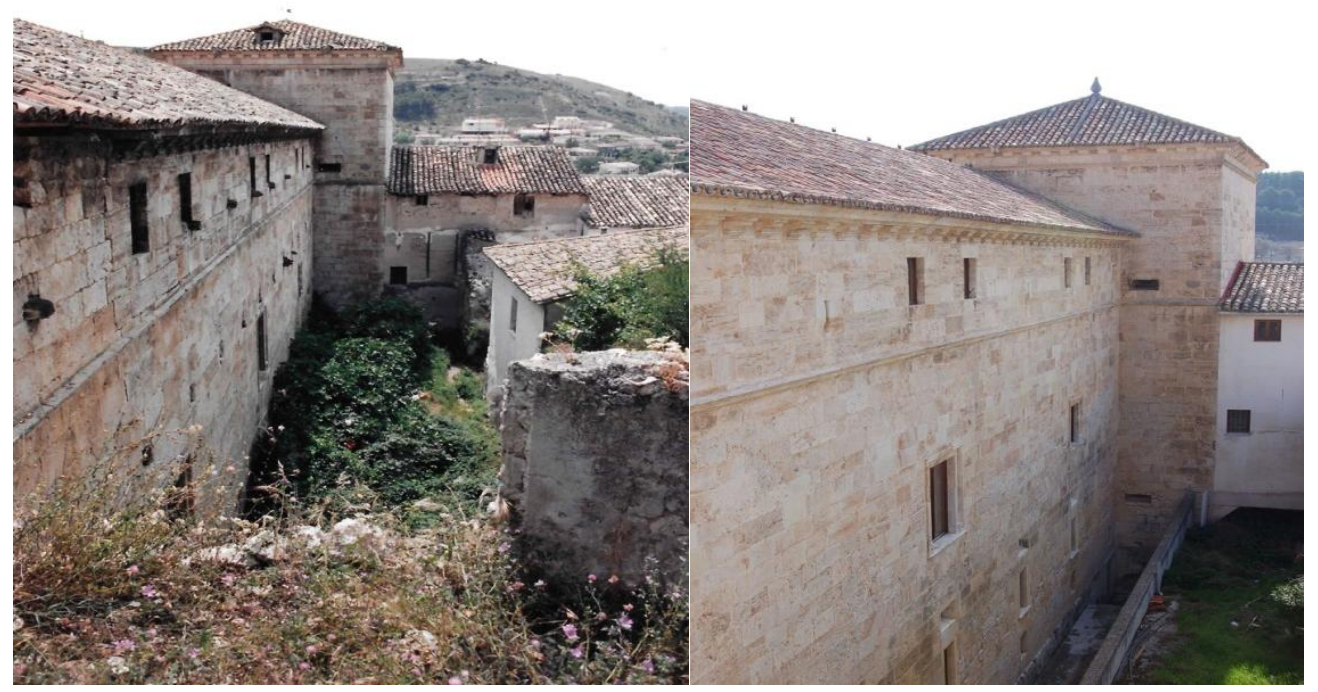

Fig. 11- Alzado oeste, antes y después de la intervención.

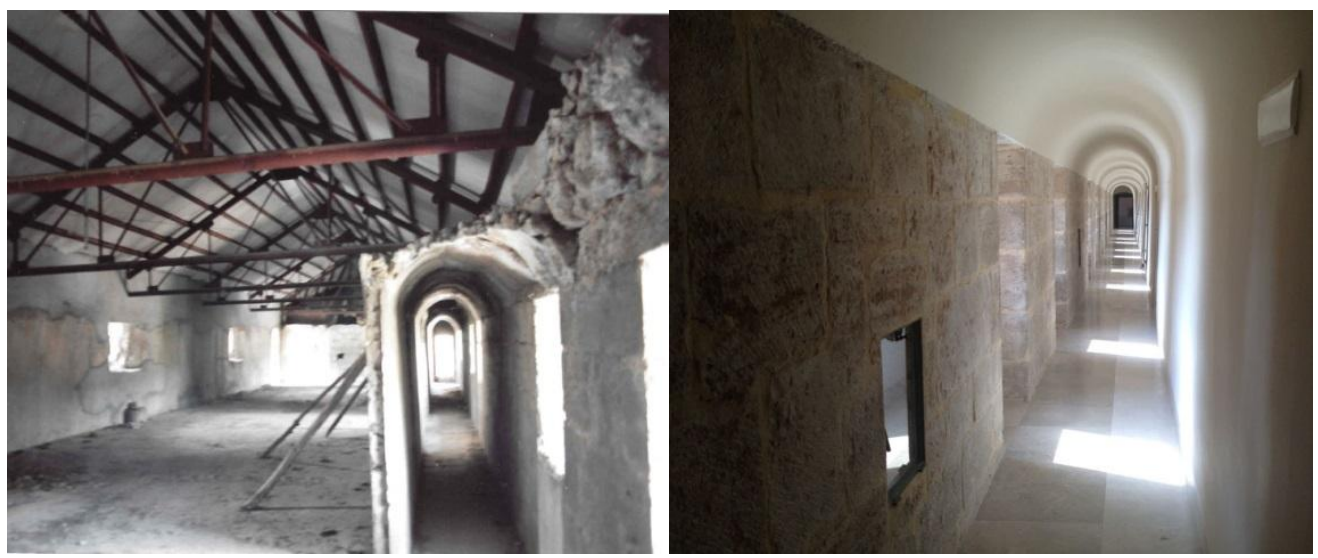

Fig. 12-Corredor de planta segunda que da acceso a las ventanas y saeteras de las fachadas, antes y después de la intervención. 


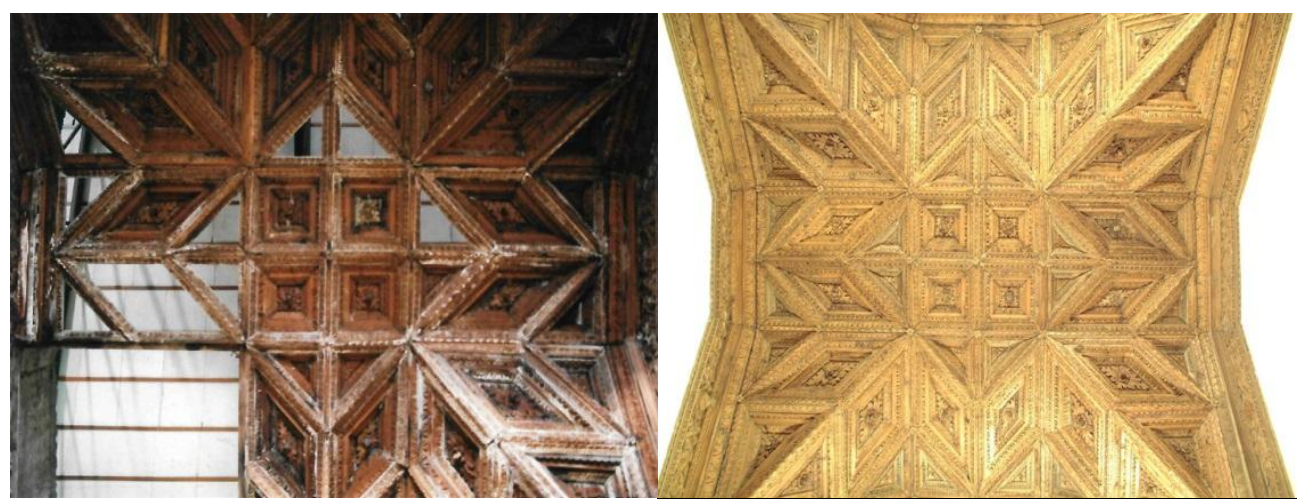

Fig. 13-Artesonado de la capilla, antes y después de la intervención

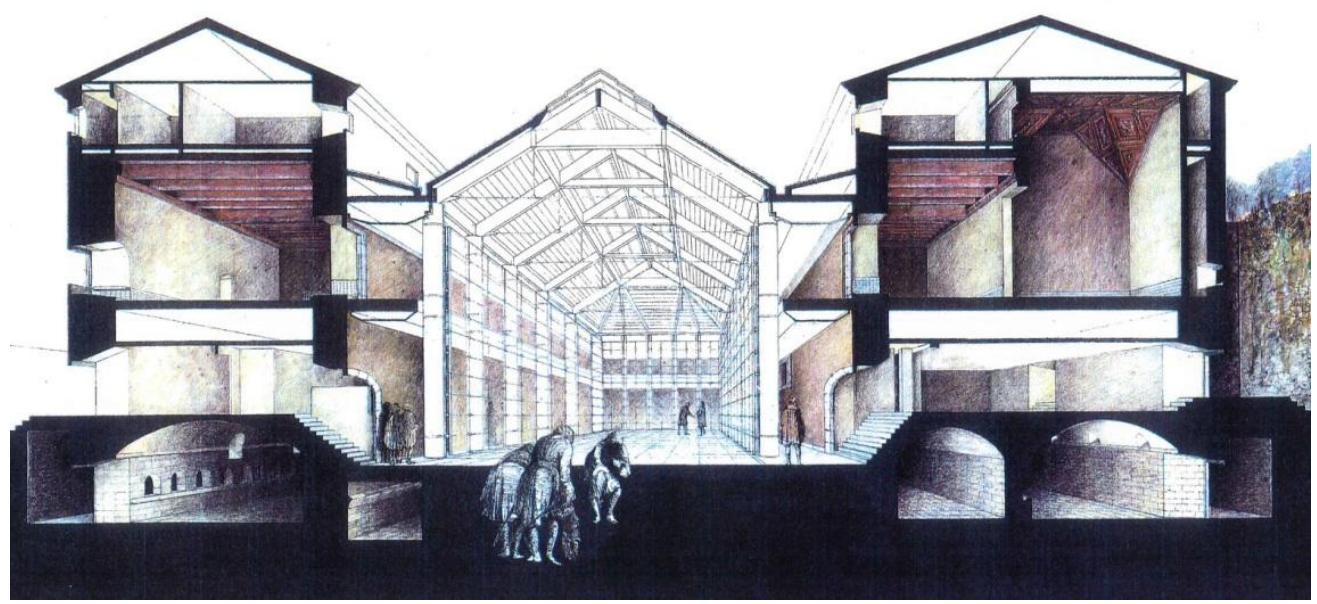

Fig. 14- Perspectiva en sección paralela a la fachada principal del edificio reformado.

\section{Referencias}

Alegre Carvajal, E., Nieto Taberné, T., y A. Fernández. (2003), La villa ducal de Pastrana, AACHE, Guadalajara.

García López, A. (2010), El Palacio Ducal de Pastrana: una obra desconocida de Alonso de Covarrubias : un libro para conocer su historia, Aache, Guadalajara.

Nieto Taberné, T. y E. Alegre Carvajal. (1999), Los jardines de la villa de Pastrana, Aache, Guadalajara.

Herrera Casado, A. (1992), Pastrana: una villa principesca: una guía para conocerla y visitarla, AACHE, Guadalajara.

Prieto Bernabé, J.M. (1986), La venta de la jurisdicción de Pastrana en 1541: la creación de un nuevo señorio, CSIC, Centro de Estudios Históricos, Departamento de Historia Moderna, Madrid

Santos Vaquero, A. y A.C. Santos Martín, (2003), Alonso de Covarrubias: el hombre y el artífice, Azacanes, Toledo.

Serrano Belinchón, J.1., García Yagüe, L. y S. Ranera. (2000), Pastrana, Iglesia-Colegiata y Museo, Parroquia de la Asunción, Pastrana, Guadalajara. 